of stricture of the pylorus of a non-malignant character pyloro-plasty-the ingenious operation suggested by Mikulicz and Heinke almost contemporaneously-seems to be by far the most satisfactory in its results. It has been practised pretty extensively on the Continent and in America, and attention was drawn to the operation by Keen of Chicago ${ }^{1}$ last February. I am not aware, however, that any case has been hitherto recorded as having occurred in England.

Newcastle.on-Tyne.

\section{SOME POINTS IN THE ETIOLOGY AND PATHOLOGY OF DIABETES MELLITUS.}

BY R. T. WILLIAMSON, M.D. LoND., M.R.C.P., MEDICAL REGISTRAR, MANCHESTER ROYAL INFIRMARY.

DuRING the last four years seventy cases of diabetes rnellitus have come under my observation at the Manchester Infirmary and elsewhere, some of which have presented points of interest respecting the etiology and pathology that seem worthy of being recorded.

\section{Di.1BETES AND THE NeRvous System.}

CASE 1. MIrrked ataxia of sudden onset; paralysis of right in ternal rectus; tremor of right arm; onset of diabetes seven weeks after commencement of symptoms. - J. W_ - aged forty-eight, was admitted under the care of Dr. Steell to the Manchester Infirmary on May 7th, 1890. Patient was quite well until April 26th, 1890. On the morning of that day, when going to his work, he suddenly became ataxic and fell to the ground. No loss of consciousness, no paralysis of limbs. He has been unable to walk or stand since, owing to ataxia. History of alcoholism; no syphilitic history. On admission, patient is unable to stand alone; when well supported he is able to adrance $a$ few steps and throws forwards his right leg in a jerky, irregular manner. Marked ataxia; no paralysis of limbs; no rigidity; knee-jerks present; no ankle-clonus. Right palpebral fissure smaller than left; a pparent ptosis of right eye; paralysis of right internal rectus; left pupil larger than the right. Slight nystagmus; slight tremor of the right arm when the limb is supported, but this is more marked on roluntary movement. Optic dises normal. old perforation of right tympanic monbrane. Temperature normal. Urine 1015, acid, no albumen, no sugar, quantity normal.-June 12th Amount of urine increased to $92 \mathrm{oz}$. - 15th: Urine pale, clear, 1024, acid, contains a large amount of sugar.-23rd : Great thirst, voracious appetite. During the first three weeks of the diabetic symptoms the amount of urine varied from 160 to $190 \mathrm{oz}$. and the sugar from 3200 to 4200 grains daily. The amounts of urine and sugar were both diminished by restricted diet. A few months later several large carbuncles developed on the gluteal region, but in course of time these and the paralysis of the right internal rectus, the ptosis and nystagmus disappeared. The diabetic symptoms, the tremor of the right hand and the ataxia persisted.

CASE 2. Tumour of the pituitary body.-A. H-, aged wwenty-three, was admitted under the care of Dr. Ross to the Manchester Infirmary on Nov. 16th, 1890. ${ }^{2}$ History of headache and gradual enlargement of hands and feet; symptoms of acromegaly. Temporal hemianopsia of the right field of vision; in the left field vision entirely lost, with the exception of a very small area near, but a little to the temporal side of, the centre of the field. Urine 1035; no albumen, no sugar; loaded with urates. After remaining in the hospital for several weeks the specific gravity of the urine rose to 1045, and it was found to contain sugar by Fehling's test, by the phenyl hydrazin test and also by fermentation. The amount of sugar at first was fourteen grains to the ounce the amount of urine normal. The sugar gradually increased in amount. The patient left the hospital for several months and then returned on account of an abscess which had dereloped in the left breast. She was admitted on the surgical side under the care of Mr. Southam. The patient complained of thirst and on examination of the urine a large amount of sugar was found. The abscess was opened and treated antiseptically and the patient put on diabetic diet. The thirst, however, increased and five days later the patient ried of diabetic coma. 'The temperature remained practically normal. At the post-mortem examination a round-celled sarcoma of the pituitary body was found, which pressed on the optic chiasma, and in which the left optic nerve was embedded. 'I'he rest of the brain was normal. The thyroid was a little enlarged and contained a colloid cyst. There were changes in the pancreas, which will be afterwards described. Liver enlarged; weight 5 lb. 2 oz. ; signs of fatty degeneration.

The following is a good example of diabetes following an injury to the head:-

CASE 3.-M. A. R-, aged eighteen, was admitted under the care of Dr. Steell to the Manchester Infirmary. The patient was a strong, healthy, stout girl up to the time of an accident seven months before admission. On going, downstairs she suddenly slipped and fell down thirteen step's, the top of her head coming violently in contact with a door at the bottom of the steps. She was stunned by the fall, but did not lose conscionsness. A dish which she had in her hand at the time was broken in the fall and her face was cut by the broken porcelain just below the right eye. She received a deep cut on the flexor surface of the right forearm just below the elbow. She had great pain in the head for many hours after the fall and has frequently suffered from severe headache since. Two weeks after the accident she first noticed thirst, which was soon followed by wasting. On admission, the patient was emaciated; knee-jerks absent; urine acid, 1045, no albumen; large amount of sugar present (twentythree grains to the ounce); marked brownish-red colouration with $\mathrm{Fe}_{2} \mathrm{Cl}_{6}$. During the time the patient was in the hospital the amount of urine at first varied from 80 to 90 ounces daily; later from 56 to 68 ounces daily, with increase of sugar to 33 grains per ounce.

The next case is one of diabetes following great mental anxiety, in which purulent cerebro-spinal meningitis and multiple abscesses in the liver were found post portem. It is difficult to say what was the relation of the cerebro-spinal meningitis and liver abscesses to the diabetes. Even supposing these changes were due to some complication, they are so rare as to be not unworthy of brief record. A similar case is published by Frerichs.

CASE 4. - J. R came under my care on Sept. 28th, 1890 History of an attack of vertigo and vomiting in February, 1890. Five weeks later he began to be troubled with thirst and polyuria. He had been unemployed for eleven months; had lost a large sum of money and been subject to great mental anxiety before onset of diabetes. $\mathrm{He}$ had obtainen employment, however, at a bleaching works about one month before he first noticed diabetic symptoms. A brother died of diabetes. When first seen the patient was considerably wasted. He suffered from thirst and polyuria. Urine 1032, acid ; large amount of sugar present ( $1 \mathrm{cc}$. of urine contained 0.0517 gramme of sugar); no albumen. Knee-jerks absent. Commencing cataract in each eye. Bowels regular. Heirt, lungs, liver and spleen normal. Four months later he was admitted as an in-patient at the Manchester Infirmary under the care of Dr. Ross. During the time he was in the hospital (six weeks) the amount of sugar varied from 2500 to 4800 grains daily and the amount of urine from 90 to $130 \mathrm{oz}$. From his admission (Jan. 21st, 1891) until Feb. 24th the temperature was normal. At the latter date the ercuing temperature was $102^{\circ} \mathrm{F}$.-Feb. 25th : Patient complaine' of pain in the epigastrium. Urine contained for the first time a trace of albumen, and also gave for the first time a clirk reddish-brown colouration with $\mathrm{Fe}_{2} \mathrm{Cl}_{6}$. Bowels constipated. For the next three days the evening temperature was between $102^{\circ}$ and $102.8^{\circ}$; then for four days the evening temperature was between $99^{\circ}$ and $100^{\circ}$..-March 4th: Evening temperature $102^{\circ}$; pulse 96 ; respiration $25,-5$ th: Morning temperature $99.6^{\circ}$; evening $1032^{\circ}$. -6th: Morning temperature $101.2^{\circ}$; evening $100^{\circ} 2^{\circ}$. Patient complained of pain in the right hypochondriac region. Edge of liver felt abont one inch and a half below the ribs. No jaundice; no rigors. Patient became very restless and semi-conscious. Kneejerks absent; calf muscles tender; no paralysis ; no anæsthesia. He could be roused to answer questions until just shortly before his death at 2 A.M. on March 7th. Shortly before death the pulse was 224 ; respiration 72 . No discharge from ears or symptoms of suppurative otitis media during the patient's illness.

Necropsy (abstract).-Peritoneum, pericardium, heart and aorta normal. Lungs, adhesions at right apex; small pat ch of broncho-pneumonia on left lower lobe and another at right apex. Left apex puckered; several small calcareous ncilules and cicatrices. Kidneys normal; suprarenal capsules, metulla of each congested; two small yellowish nodules in medulla 
of right capsule. Spleen slightly enlarged and pulpy, weight eleven ounces. Pancreas (weight two ounces and a half) somewhat small and firm. Liver (weight five pounds), capsule normal ; on section scattered irregularly throughout the right lobe, but most numerous in the outer half of the right lobe, are a number of small abscesses varying in size from a pea to a marble. Near the right border these are clustered together so as to form a large suppurating patch four inches transversely by two inches and a half vertically. The pus can be washed away, leaving small carities. At only a few places is there any zone of hyperæmia around the abscesses. Gallbladder contains a small amount of orange-coloured bile; mucous membrane slightly congested, but no ulceration can be detected. No obstruction of cystic, hepatic or common bile-ducts. Large bile-ducts can be traced in liver substance for a considerable distance, but nothing abnormal detected. No thrombus in portal vein or any of its larger branches. Stomach : no ulceration or other abnormality of importance. Rectum, prostate and bladder normal. Spinal cord ; dura mater normal. On opening dura mater, meninges of posterior surface of cord, in dorsal region, very turbid and yellowish in colour ; in cervical and lumbar region, turbidity not quite so well marked. Vessel of posterior aspect of cord much distended; only slightly distended in anterior aspect. Turbidity of meninges on anterior surface. On section of the cord nothing abnormal detected. Cord hardened in Müller's fluid. Sections in all parts normal to the naked eye (excepting meninges) ; microscopical examination confirmed the diagnosis of purulent lepto-meningitis. Skull cap, cerebral dura mater and blood sinuses normal ; base of skull, including regions of petrous portions of temporal bones, normal. Meninges of each cerebral hemisphere turbid and yellowish; distinct suppuration at the sulci. At the anterior part of the first left frontal convolution is a hæmorrhage about the size of a halfpenny, irregular in shape, situated between the arachnoid and the cortex; and passing down between the convolutions, but not entering the brain substance. The meninges of the upper surface of the cerebellum present the same appearance of purulent meningitis as those of the cerebral cortex. The membranes of the base of the brain appear normal. A small amount of turbid fluid is present in the lateral ventricles and a small amount of pus in the posterior horn of the left lateral ventricle. In the fourth ventricle nothing abnormal detected. Apart from the changes just mentioned the rest of the brain-basal ganglia, cerebral hemispheres, cerebellum, pons and medulla-appear normal. Microscopical examination confirmed the naked-eye appearances of purulent lepto-meningitis. Sections of the pons and medulla showed slight dilatation of the vessels at the floor of the fourth ventricle, but no other microscopical changes.

In the history of some of the seventy cases of diabetes there were several other points of interest. Thus great mental anxiety and worry due to loss of money, loss of employment \&c., were antecedents in nine cases. In one case the symptoms came on whilst the patient was preparing for the Final B. A. Examination Lond. For a long period he had devoted almost the whole of his time, with the exception of that required for sleep and meals, to the closest study. In one case the patient had been subject to epileptic fits for several years.

As regards heredity, in one instance three sisters all suffered from diabetes. In six other cases there was a family history of diabetes. In eight cases there was a long history of very great alcoholic excess up to the time of onset of diabetic symptoms. In two cases the symptoms came on during an attack of pleurisy. In another case diabetes came on during prolonged lactation; marked wasting soon occurred and the patient died about twelve months after the onset of symptoms. I have notes of another case, in which diabetes followed a mammary abscess soon after confinement. In one case symptoms of diabetes came on during influenza, in another case during a severe cold.

\section{Diabetes and Lesions of the Pancreas.}

Changes in the pancreas are of great interest, since Minkowski and v. Mering showed by their famous experiments in 1889 that diabetes could be produced in dogs by total extirpation of the pancreas. ${ }^{3}$ I have examined the pancreas in four cases of diabetes.

CAsE 1. Marked cirrhosis of the pancreas. - T. L-, aged forty-five (under the care of Dr. Ross at the Manchester

3 For discussion of the relatinn of lesions of the pancreas to diabetes, and for complete notes of the cases of T. L- and T. S-, see paper in Medical Chronicle, Alarch, 1892.
Royal Infirmary). Diabetes mellitus, with wasting. Peculiar pinkish tinge of the urine. History of great alcoholic excess, Death by coma. Necropsy : Pancreas weighed four ounces and a quarter; was very hard and was cut with difficulty. Section showed to the naked eye that the organ was infiltrated with dense fibrous tissue, in which small masses of the remaining gland tissue were embedded. There wene several small cystic dilatations of the pancreatic duct, containing small calculi and mucous fluid. Microscopical examination showed a very great excess of fibrous tissue. In some places almost the whole of the field of the microscope was occupied with dense fibrous tissue. At some parts small clusters of pancreatic cells, at other parts small lobules of degenerated pancreatic tissue, were seen embedded in the fibrous tissue. With the exception of a cavity and other tubercular changes in the right lung examination of the liver, brain and other organs revealed nothing of importance. CASE 2. Atrophy and fatty degeneration of the pancreas.T. S- (under the care of Dr. Mackenzie, Victoria Hospital, Burnley). Diabetes with wasting. Death by coma. Necropsy : Pancreas markedly atrophied, exceedingly soft and flabby, weight one ounce and a quarter; on section studder? with pale spots. Microscopical examination of sectious stained with osmic acid showed marked fatty changes, especially at the pale spots. At many parts the pancreatic cells contained small fat globules. Mingled with these degenerated cells were fat cells, some small, others very large. In some parts the fatty changes occupied the centre, at other parts the periphery of a lobule.

The pancreas in the case of A. H- (tumour of the pituitary body), above described, was very largeand heavy. It weighed six ounces. Microscopical examination showed a marked excess of interlobular fibrous tissue, which in some parts was richly supplied with nuclei. In this interlobular connective tissue many large clusters of fat cells were embedded, also in the interior of many of the lobules, groups of large fat cells were scattered. Whether the diabetes in this case was produced directly by the tumour of the pituitary body or indirectly. through secondary pancreatic changes it is impossible to say.

In the case of J. R-, above described, the pancreas appeared normal microscopically.

[To Drs. Steell, Leech, Ross, Dreschfeld and Mackenzie, and to Mr. Southam I am indebted for kindly giving me the opportunity of observing some of the above cases.]

\section{Clinital atotes:}

\section{MEDICAL, SURGICAL, OBSTETRICAL, AND THERAPEUTICAL.}

\section{ON THE TREATMENT OF CLOTTED BLOOD IN THE BLADDER BY AN EVACUATOR.}

B Y H. A. LEDIAR D, F.R.C.S. ENG., SURGEON TO THE CUMBERLAND INFIRMARY.

ON somewhat rare occasions the surgeon has to deal with troublesome hæmorrhage into the bladder, where the blood in place of mixing with the urine and passing out naturally becomes clotted, and where further bleeding goes on so as to cause a painful distension of the bladder. In such a case a catheter is passed without affording relief, for the eye of it is instantly plugged. Bleeding continues owing to the presence of clot much in the same way as post-partum hæmorrhage lasts, so long as a clot prevents contraction of the uterus. Among the causes of intra-vesical hæmorrhage villous tumour occupies the first place, for the bleeding is sometimes rapid and the clotting firm; other malignant growths bleed, but, verhaps, less severely. Hæmorrhage is associated with enlarged prostate and ruptures of the bladder, but in the latter most of the blood will be intra-peritoneal. Hæmorrhage after lithotomy is usually external, but according to Erichsen venous hæmorrhage after lithotomy is apt to find its way back to the bladder and may coagulate and distend that organ. Whatever the cause may be, the object held in view is to empty the bladder, and this is by no means easy, for clots will not pass through an ordinary catheter, even when a stream of water is now and then injected down the catheter to keep the eye clear; neither will clots pass 